\title{
Effectiveness of resonance frequency in predicting orthopedic implant strength and stability in an in vitro osseointegration model
}

\author{
Brad M. Isaacson, BS; ${ }^{1-2 *}$ Richard E. Vance, BS; ${ }^{3}$ Teri G. Rosenbaum Chou, PhD; ${ }^{4}$ Roy D. Bloebaum, PhD; ${ }^{1-3}$ \\ Kent N. Bachus, PhD; ${ }^{1-3}$ Joseph B. Webster, MD $^{1,5}$ \\ ${ }^{1}$ Bone and Joint Research Laboratory, Department of Veterans Affairs Salt Lake City Health Care System, Salt Lake \\ City, UT; ${ }^{2}$ Department of Bioengineering, University of Utah, Salt Lake City, UT; ${ }^{3}$ Department of Orthopaedics, \\ University of Utah, Salt Lake City, UT; ${ }^{4}$ Orthocare Innovations, Seattle, WA; ${ }^{5}$ Department of Physical Medicine and \\ Rehabilitation, University of Utah, Salt Lake City, UT
}

\begin{abstract}
Developing noninvasive tools that determine implant attachment strength to bone and monitor implant stability over time will be important to optimize rehabilitation protocols following insertion of osseointegrated implants in patients with limb loss. While resonance frequency has been previously shown to correlate with implant stability in dental implants placed in the mandible and maxilla, this tool has not been evaluated with implants placed in the medullary canal of long bones. In an in vitro model used to simulate irregular medullary canal implant contact and osseointegration, a strong positive correlation was determined between resonance frequency implant stability quotient values and the force required for implant pushout. The force required for implant displacement also correlated to the distance from the point of fixation to the transducer at the proximal end of the implant (point of resonance frequency monitoring).
\end{abstract}

Key words: bone, bone-implant interface, implant stability, limb amputation, mechanical testing, osseointegration, outcomes, rehabilitation, resonance frequency, skeletal fixation.

\section{INTRODUCTION}

The term "osseointegration" has been used to describe a structural and functional connection between living bone and the surface of a load bearing implant [1-2]. Successful osseointegration techniques have been previously demon- strated for individuals with limb loss [3-5], as well as in the areas of dentistry [1-2,6-8] and craniofacial reconstruction [6]. As a result of an increased desire for functionality for patients with transfemoral, transhumeral, and transtibial amputations [3,9-11], osseointegration technology has been developed for direct skeletal attachment of an exoprosthesis to the residual limb. With the osseointegration procedure for persons with limb loss, a biocompatible metal fixation is surgically inserted directly into the bone of the residual limb and serves as an attachment system for connecting and suspending a prosthesis to the residual limb [5,12-13].

One challenge with the use of natural biological skeletal fixation is allowing the bone to heal and osseointegrate with the implant surface, thereby attaining a strong skeletal

\footnotetext{
Abbreviations: $\mathrm{ABS}=$ acrylonitrile butadiene styrene, ISQ = implant stability quotient, RFA = resonance frequency analysis, $\mathrm{SD}=$ standard deviation, $\mathrm{VA}=$ Department of Veterans Affairs.

* Address all correspondence to Brad M. Isaacson, BS; Bone and Joint Research Laboratory (151F), VA Salt Lake City Health Care System, Salt Lake City, UT 84148; 801-5821565, ext 4122; fax: 801-584-2533.

Email: brad.isaacson@utah.edu

DOI:10.1682/JRRD.2009.02.0012
} 
interlock, a prerequisite for long-term implant function and stability [14-15]. To prevent mechanical loosening at the bone-implant construct, current osseointegration rehabilitation protocols require extensive periods of restricted load bearing to allow sufficient bone attachment and prevent overloading at the bone-implant interface [12,16-24]. Limiting the force on the periprosthetic bone following insertion of an osseointegrated implant is based on the principle that stress must be exerted gradually to promote firm skeletal attachment, since under- or overloading may compromise the integrity of the host bone. However, previous literature indicates that immediate implant loading may not compromise the integrity of the bone-implant interface or prevent osseointegration if micromotion is controlled in properly designed implants [15,17-19,23-27].

The inability to quantitatively diagnose implant fixation has driven scientists and physicians alike to develop clinical tools to assess primary and secondary implant stability. Primary implant stability occurs immediately after surgical placement [28], and successful osseointegrated implants result from proper implant fit and fill [29] and surgical techniques [30-32]. However, secondary implant stability is the result of bone healing and remodeling that occurs over time [33]. While initial implant fixation is required to prevent micromotion and fibrous encapsulation [16,19,34-40], the long-term success of osseointegrated implants requires firm skeletal connections that may not occur until 9 months postoperative in human cancellous bone [16] and would be more representative of both primary and secondary implant stability.

Since no quantitative measures exist to determine optimal skeletal attachment in vivo, current European and Australian rehabilitation programs for transfemoral amputees with osseointegrated implants require slow, progressive weight bearing [41-42]. Methods for assessing osseointegration strength and stability have included mechanical testing, light microscopy, and scanning electron microscopy [43-46]; however, these techniques for evaluating skeletal fixation cannot be used in dental applications and for patients with limb loss because of the invasiveness [46-47]. Therefore, alternative means of assessing implant stability have been developed and include radiographs, percussion tests, and resonance frequency. Radiographs, however, are not sensitive for determining the extent of osseointegration [48] since a reduction in bone mineralization of 40 percent [49] is required before bone mineral loss can be accurately deter- mined. An examination of radiolucencies with plain radiographs has shown to result in approximately 2 percent false-positive diagnoses of inadequate osseointegration and implant loosening [50]. In addition, traditional radiographs require standardization with threaded implants [21], since reproducibility is difficult and essential in preventing unnecessary surgical revisions [50]. Advanced imaging techniques such as computed tomography scans are also not practical because of expenses, image artifact generated from metal implants, and high exposure to radiation [51].

Percussion tests have also been used to assess osseointegration implant stability, but this technique is considered generally inadequate in the clinical setting. When implant stability is evaluated with percussion tests using dental implants, the procedure often results in "more information about the tapping instrument, and will at best only reveal poor qualitative information" [52]. Therefore, percussion tests are limited since the process only provides quick distinction between mobile and osseointegrated implants but does not reveal the degree of implant stability and thereby restricts the ability of rehabilitation specialist to monitor and advance progressive weight-bearing regimens [53].

A potentially useful noninvasive alternative is resonance frequency analysis (RFA), which has been shown to correlate with the degree of implant stability in dental implants [21,44,47-48,52-55]. Fluctuations in implant stability quotient (ISQ) values even mimic expected bone remodeling rates $[20,54,56]$. Several studies have also reported that ISQ values decrease within the first 3 months postoperative [20,57-58], as a result of osteoclast resorption, which is key to increased osteoblast activity and new bone formation [33,59]. The reliability of resonance frequency has been confirmed with ISQ values but is dependent on jaw position [44,53] and attributed to the differences in bone quality and type [17, 37-38,43,60].

The resonance frequency system most commonly used with dental implants and reported in the literature is the Osstell Mentor ${ }^{\circledR}$ (Osstell AB; Gothenburg, Sweden). This device uses a compact battery system and magnetic pulse to monitor ISQ values [61]. The handheld probe is attached to a docking station, and a magnetic pulse is transmitted to a Smartpeg (Osstell AB) temporarily attached to the proximal face of the implant [41,44]. With use of a bode plot function [61], the response signal is translated into a numerical ISQ value, which may be used 
to determine the degree of implant stability. Extensive review articles evaluating the performance of the Osstell device are also available but are not within the scope of this narrative [49,52]. While RFA has been shown to effectively determine osseointegration implant stability in edentulous mandible and maxilla models, ours is the first study to evaluate the utility of this device in an in vitro model simulating irregular osseointegration in a long bone medullary canal.

The objective of this study was to determine a biomechanical relationship between RFA ISQ values and the force required to displace a titanium alloy implant. A composite fixture was utilized to improve reproducibility, which arises from the use of a more uniform material type. Establishing a relationship between torque, attachment location, and resonance frequency with mechanical pushout forces would provide valuable information as a basis for further in vivo testing, because currently no biomechanical testing data directly relate resonance frequency to load bearing. Clearly, new developments in orthopedics and rehabilitation will continue to demand advanced tools for patients seeking osseointegrated implants following limb loss. Therefore, the ultimate goal of this research is to utilize resonance frequency for optimizing the speed and safety of rehabilitation for amputees with osseointegrated implants, since skeletal fixation will vary between persons [49], and individual rehabilitation programs will be required.

\section{METHODS}

\section{Testing Fixture and Implant Design}

An implant fixation construct was designed to simulate percutaneous, osseointegrated implant attachment in a medullary canal and was built in a three-dimensional printer (Dimension Elite, Stratasys Inc; Eden Prairie, Minnesota) utilizing layered acrylonitrile butadiene styrene (ABS) plastic. The completed fixture was $45 \mathrm{~mm}$ in height by $30 \mathrm{~mm}$ in width with a $4 \mathrm{~mm}$ hole centrally located for implant attachment. An ABS model was selected as the testing material because it excludes the inherent variability of human cadaveric bone [62-64]. In addition to variability between bone specimens, dehydrated bone will exhibit a higher modulus of elasticity caused by the diffusion of water into vacant spaces and stiffening of collagen fibers [65]. This decrease in water content, which may occur during biomechanical testing, will subsequently lead to the host bone becoming brittle and exhibiting reduced plasticity [65] and may lead to inaccurate data collection. Since the protocol was initially targeting the precision and accuracy of the resonance frequency technique for potential use in patients with osseointegrated implants, a standard material type was selected.

Titanium alloy (Ti-6Al-4V) implant analogs, $20 \mathrm{~mm}$ in length, were manufactured to investigate the utility of the resonance frequency device. Implants were fabricated as one unit and included a hexagonal head ( $5 \mathrm{~mm}$ in height by $8 \mathrm{~mm}$ in width) and a smooth post distally (15 mm in length and $3.5 \mathrm{~mm}$ in diameter). The hexagonal design included an $8 \mathrm{~mm}$ base to fit securely on the ABS device and prevent translation and rotation during data collection (Figure 1). Titanium alloy was also selected as the implant material based on its frequent successful use in total joint replacements [66-67], biocompatibility [6869], and nonferromagnetic properties [70-71] that would not alter RFA recordings.

Three $3 \mathrm{~mm}$ holes were evenly spaced and drilled $5 \mathrm{~mm}$ apart in the ABS fixture to represent partial osseointegration along the titanium implant insert (Figure 1). Setscrews

(a)

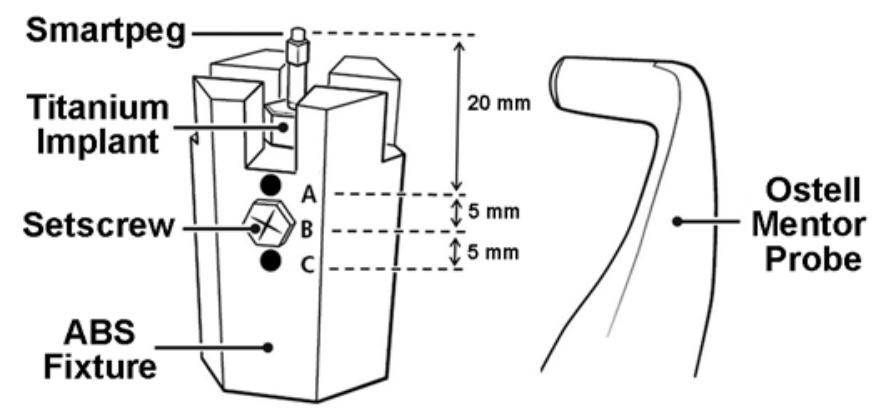

(b)

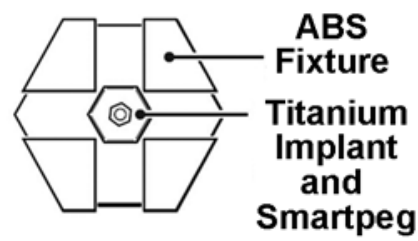

Figure 1.

Spatial position of each hole (A, B, and C) is depicted in simulated osseointegration model. Hole A was located $20 \mathrm{~mm}$ from most proximal aspect of Smartpeg, with each hole increasing in distance by $5 \mathrm{~mm}$, respectively. (a) Front and (b) top views. ABS = acrylonitrile butadiene styrene. 
were fixed at multiple insertion torques and levels to prevent the smooth titanium implant from migrating and to simulate a series of nonuniform bone-implant interfaces and depths, since the quality of osseointegration cannot be assumed to be uniform along the bone-implant construct. In the ABS fixture, Hole A was located $20 \mathrm{~mm}$ from the most proximal aspect of the Smartpeg and each additional hole positioned $5 \mathrm{~mm}$ distally. Implants were secured with torques ranging from 5 to $12.5 \mathrm{~N} \cdot \mathrm{cm}$, since 5 to $50 \mathrm{~N} \cdot \mathrm{cm}$ is regarded as necessary for primary implant stability [47]. Therefore, to ensure accurate data collection in this model and avoid exceeding the elastic limit of the setscrews, we chose $12.5 \mathrm{~N} \cdot \mathrm{cm}$ as the highest evaluated torque. A range of torques was also selected in the in vitro model, since the initial fixation required for successful osseointegration is unknown [47] and depends largely on bone quality and density [72].

\section{Resonance Frequency Analysis}

The Osstell measurement system (Osstell Mentor ${ }^{\circledR}$ ) designed for oral cavity and craniofacial implants was used to obtain the resonance frequency values. Smartpegs were attached to the titanium alloy implants and received magnetic pulses to determine implant fixation strengths. The threaded Smartpegs (Type 1) were consistently torqued to $10 \mathrm{~N} \cdot \mathrm{cm}$ with a hand-held, digital torque meter (Advanced Force/Torque Indicator, Dillon Quantrol; Fairmont, Minnesota), and ISQ values were recorded before mechanical testing, based on recommendations from previous RFA literature [47]. An insertion torque of $10 \mathrm{~N} \cdot \mathrm{cm}$ was also selected since it was regarded as least likely to damage the Smartpeg's screw threads [21] and would ensure accurate data collection.

Skeletal fixation was simulated with six variable torques $(5.0,7.0,8.6,10.0,10.9$, and $12.5 \mathrm{~N} \cdot \mathrm{cm})$ at three separate fixation locations (Hole A, Hole B, and Hole C) (Figure 1). Screw torques were randomly selected within the predetermined range and verified with the digital torque meter before data collection. After recording three ISQ's values on each orthogonal face to ensure implants were properly loaded on all axes, to demonstrate repeatability, and per manufacturer instructions [44], we removed the Smartpegs and positioned the implant below the crosshead of the mechanical testing apparatus (Model 8800, Instron Corp.; Norwood, Massachusetts). Smartpegs were discarded and replaced after three measurements to avoid screw thread wearing.

\section{Mechanical Testing}

Implants were secured in the ABS fixture, placed in the servohydraulic mechanical testing device, and preloaded to $30 \mathrm{~N}$ in a load-controlled testing mode. Load was increased steadily at a rate of $5 \mathrm{~N} / \mathrm{s}$ (a recommended loading rate established by the mechanical engineering coauthors) until implant displacement occurred. All data were sampled continuously at $100 \mathrm{~Hz}$ throughout the mechanical-testing procedure (Figure 2). To prevent observer bias, we determined the exact point of implant displacement with a custom script (MATLAB, The MathWorks Inc; Natick, Massachusetts). The code was generated to determine a 3 percent change in slope for the continuous data, and the data point that corresponded with the initial change in slope was selected as the ultimate failure load. A 3 percent change in slope between position and time accounted for the specific tolerance of our mechanical testing system, as well as a safety factor of 1 percent. Therefore, a 3 percent relative difference in slope would likely account for measurement error and system noise and prevent subjective interpretations of implant displacement.

To make certain that the implant construct was not damaged from repeated mechanical-testing usage, the ABS fixture was carefully bivalved (Craftsman $10 \mathrm{in}$.

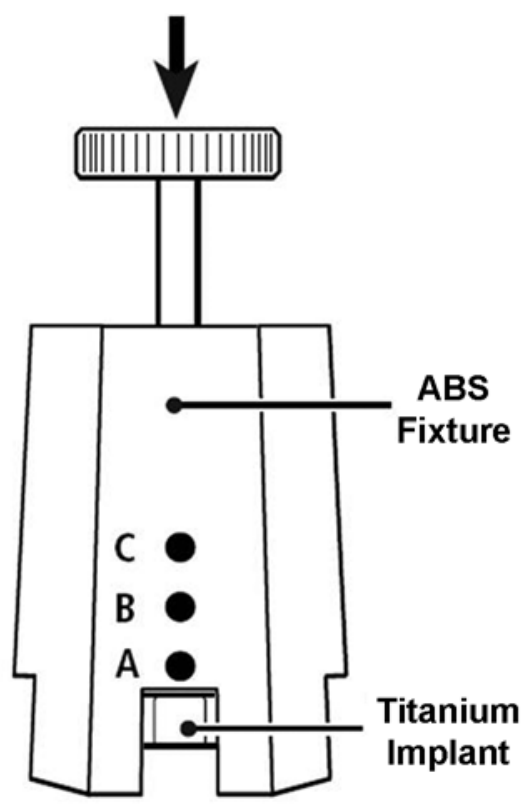

Figure 2.

After resonance frequency implant stability quotient values were recorded three times on each orthogonal face, Smartpeg was carefully removed and implant was preloaded with $30 \mathrm{~N}$ and pushed out of acrylonitrile butadiene styrene (ABS) fixture. 
Direct Drive Band Saw, Sears Holding Corporation; Hoffman Estates, Illinois) and examined with a laboratory macroscope (Nikon SMZ800, Nikon Inc; Melville, New York) equipped with imaging capturing software (Magnafire SP, Optronics; Goleta, California) at the conclusion of the pushout tests. Investigating the inner wall of the fixation device was important for ensuring that damage did not occur and alter the surface area for implant attachment or affect the predetermined loading conditions. Extensive examination of the construct did not reveal visible imperfections from mechanical testing and helped demonstrate repeatability and accuracy during data collection.

\section{Statistical Analysis}

A multiple linear regression was used to correlate the outcome of mechanical pushout force with the predictor variables (screw torque, fixation distance, resonance frequency ISQ, interaction between resonance frequency and screw torque, and distance from Smartpeg). In one model, the distance from the Smartpeg was included as a continuous variable; in the second model, it was investigated as two dummy variables to account for the three points of fixation. In each case, the interaction between screw torque and resonance frequency was included. To avoid overfitting, at least 10 observations for each predictor variable were required in the model. In this study with a sample size of 45 , four to five variables were included and would not lead to misinterpretation of data. $R^{2}$ values are reported with each model along with the adjusted $R^{2}$ values, which represent the correlation without problems due to overfitting. All statistical comparisons were conducted with commercially available software (SPSS, Inc; Chicago, Illinois).

\section{RESULTS}

Descriptive statistics (mean and standard deviation [SD]) based on mechanical displacement forces for fixa- tion location and screw torque are provided in Table 1. When determining statistical significance, we excluded torques exceeding $10.9 \mathrm{~N} \cdot \mathrm{cm}$, since inconsistent data indicated that the elastic limit of the screws was exceeded and inclusion would have provided speculative correlations. Therefore, a total of 45 data points was collected for three fixation locations and five torques on the single fixture. Further interpretation of Table 1 demonstrates that the maximum pushout forces were consistent for Hole B, which may have resulted from fixture construction and the point of contact along the implant shaft. Additionally, data in this table suggest that the elastic limit of the setscrews was exceeded even at $10.9 \mathrm{~N} \cdot \mathrm{cm}$, since pushout forces decreased when torque increased from 10.0 to $10.9 \mathrm{~N} \cdot \mathrm{cm}$ for Holes A and B, but this trend was not evident with Hole $\mathrm{C}$ and therefore these quadrants must be treated as outliers in the data set.

A multivariable linear regression model was fit to the outcome variable (mechanical pushout forces) as shown in Table 2. The significant predictor variables were screw torque $(B=-13.40, p=0.049)$, resonance frequency $(B=$ $-2.89, p=0.012$ ) and the interaction of screw torque and resonance frequency $(B=0.38, p=0.004)$. Distance from the point of fixation, included in the model as a continuous variable, was not significant $(B=-4.00, p=0.36)$. The rationale for including distance as a continuous variable was that previous reports indicated that implant stability linearly decreases with increasing distances from the Smartpeg [55].

For verification of the linear reduction in resonance frequency ISQ values with increasing distance from the Smartpeg, a second model was fitted and distance was included in the model as dummy variables (Table 3). The first dummy variable was located $20 \mathrm{~mm}$ from the Smartpeg (Hole A)

Table 1.

Mean \pm standard deviation mechanical pushout forces independently assessed as a function of screw torque and distance from Smartpeg ( $n=3$ per combination, total $N=45)$.

\begin{tabular}{cccc}
\hline \multirow{2}{*}{ Screw Torque (N·cm) } & \multicolumn{3}{c}{ Distance from Smartpeg } \\
\cline { 2 - 4 } & $\mathbf{2 . 0} \mathbf{~ m m}$, Hole A & 2.5 mm, Hole B & 3.0 mm, Hole C \\
\hline 5.0 & $26.83 \pm 4.21$ & $35.80 \pm 3.76$ & $33.37 \pm 3.72$ \\
8.0 & $26.19 \pm 8.74$ & $46.13 \pm 3.14$ & $26.19 \pm 4.15$ \\
10.6 & $41.60 \pm 12.46$ & $47.95 \pm 9.55$ & $47.95 \pm 1.57$ \\
10.9 & $73.40 \pm 0.00$ & $79.90 \pm 3.76$ & $61.13 \pm 4.21$ \\
\hline \hline
\end{tabular}


JRRD, Volume 46, Number 9, 2009

Table 2.

Multiple linear regression model of mechanical pushout $(N=45)$, using distance as a continuous variable.

\begin{tabular}{lccc}
\hline \multicolumn{1}{c}{ Predictor Variable } & Coefficient (B) & Standard Error & $\boldsymbol{p}$-Value \\
\hline Distance & -4.00 & 4.34 & 0.36 \\
Screw Torque & -13.40 & 6.60 & 0.049 \\
Resonance Frequency & -2.89 & 1.10 & 0.012 \\
Interaction Between Resonance Frequency and Screw Torque & 0.38 & 0.12 & 0.004 \\
\hline
\end{tabular}

Note: Multiple $R=0.83$, multiple $R^{2}=0.69$, multiple adjusted $R^{2}=0.67$.

Table 3.

Multiple linear regression model of mechanical pushout $(N=45)$, using distance from the Smartpeg as dummy variables.

\begin{tabular}{|c|c|c|c|}
\hline Predictor Variable & Coefficient (B) & Standard Error & p-Value \\
\hline Screw Torque & -11.72 & 6.32 & 0.07 \\
\hline Resonance Frequency & -2.92 & 1.05 & 0.008 \\
\hline Interaction Between Resonance Frequency and Screw Torque & 0.35 & 0.12 & 0.005 \\
\hline Distance from Hole A to Hole B & -7.10 & 4.51 & 0.12 \\
\hline Distance from Hole C to Hole B & 0.35 & 0.12 & 0.005 \\
\hline
\end{tabular}

Note: Multiple $R=0.84$, multiple $R^{2}=0.71$, multiple adjusted $R^{2}=0.67$.

and the second dummy variable was located $30 \mathrm{~mm}$ from the Smartpeg (Hole C). The third position on the testing fixture was located $25 \mathrm{~mm}$ from the Smartpeg (Hole B) and acted as the reference point for the two dummy variables, since it was centrally located and the midpoint between fixation points (Figure 1). The significant predictor variables in this model were resonance frequency $(B=-2.92, p=$ 0.008 ), interaction between resonance frequency and screw torque ( $B=0.35, p=0.005$ ), and distance from Hole $C$ to Hole $\mathrm{B}(B=0.35, p=0.005)$. However, the distance from Hole A to Hole B was not significant ( $p=0.12$ ). The predictor variable screw torque had a significant trend in which increased torques resulted in higher ISQ values and added to the interaction term, but this was not statistically significant alone $(p=0.07)$. A positive correlation between resonance frequency ISQ values and screw torque has also been previously reported in an in vitro model [60] and demonstrates the reproducibility of our work with previous studies.

The relationship of resonance frequency and screw torque to mechanical pushout forces is graphically represented in Figure 3 and quantitatively described in Table $\mathbf{4}$ using the same raw data. The three-dimensional representation shows a general increase in the force required to displace the titanium implant as screw torque and resonance frequency increased. The majority of the data points collected in the model occurred at higher ISQ values (37/45), which is a trend also noted in previous dental applications [48]. For ease of understanding of the relationship, resonance frequency was subdivided into ranges of low, low-to-medium, medium, and high values, which were used to predict the degree of osseointegration. The mean and SD of each quadrant are presented in Table 4.

\section{DISCUSSION}

The prolonged recovery and rehabilitation period that currently follows osseointegration implantation (approximately 12 months from postoperative to full weight bearing

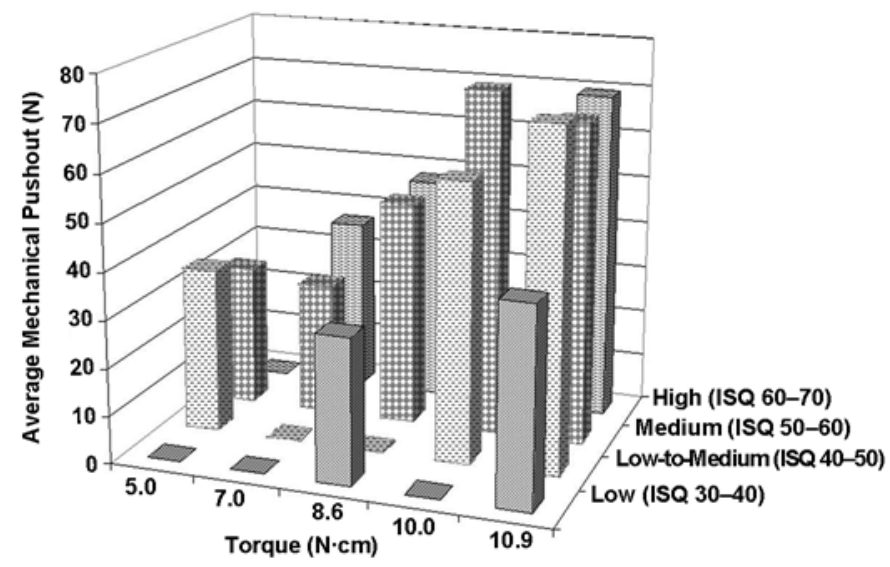

Figure 3.

Relationship between torque and average implant stability quotient values as predictor variables for mechanical pushout forces. ISQ = implant stability quotient. 
Table 4.

Force (mean \pm standard deviation) required for mechanical pushout subdivided by resonance frequency and screw torques, where “_-” signifies that no data were collected in the quadrant $(N=45)$.

\begin{tabular}{ccccc}
\hline \multirow{2}{*}{ Screw Torque (N·cm) } & \multicolumn{5}{c}{ ISQ Range } \\
\cline { 2 - 5 } & $\begin{array}{c}\text { Low, 30-40 } \\
\text { (2 data points) }\end{array}$ & $\begin{array}{c}\text { Low-Medium, 40-50 } \\
\text { (6 data points) }\end{array}$ & $\begin{array}{c}\text { Medium, 50-60 } \\
\text { (25 data points) }\end{array}$ & $\begin{array}{c}\text { High, 60-70 } \\
\text { (12 data points) }\end{array}$ \\
\hline 5.0 & - & $34.8 \pm 4.2$ & $29.8 \pm 5.3$ & - \\
7.0 & - & - & $28.0 \pm 7.0$ & $36.7 \pm 13.1$ \\
8.6 & 30.7 & - & $47.6 \pm 5.9$ & $47.9 \pm 9.6$ \\
10.0 & - & 58.7 & $73.1 \pm 7.8$ & - \\
10.9 & 41.6 & 71.5 & $67.9 \pm 5.7$ & $69.5 \pm 15.0$ \\
\hline
\end{tabular}

[73]) in individuals with lower-limb amputations demonstrates the need for a simple, noninvasive tool that determines implant strength and stability. The use of an RFAtype of rehabilitation device is anticipated to quantitatively determine the integrity of the bone-implant interface during osseointegration and increase the loading rate on osseointegrated implants, thereby shortening current rehabilitation regimens. Therefore, the aim of this study was to determine whether a relationship existed between resonance frequency and mechanical pushout forces in a carefully controlled in vitro medullary canal osseointegration model.

The correlation between screw torque and resonance frequency, as demonstrated in Figure 3, confirms the reliability of the Osstell device for predicting mechanical pushout forces in a nonuniform osseointegration model. While several data points were in the low and low-tomedium ranges, the data collected were primarily in the medium and high ranges of ISQ values and fit the published values for stable osseointegration ISQs ranging from 40 to 70 [48]. The majority of data collected in the model was in the ISQ range of 50 to 70, and the torques tested were in the vicinity of previous in vivo dental applications. While the exact ISQ value for complete osseointegration is unknown, Zix et al. report an average ISQ of $57.66 \pm 8.19$ (ISQ range: 23-73) [48], KesslerLiechti et al. report $64.50 \pm 7.90$ (ISQ range: 58-72) [53], and Zhou et al. report $53.90 \pm 7.70$ (ISQ range: 37-68) [46] in in vivo human and rabbit models. These values are in the locality of the overall mean and SD in this experiment, which was $55.74 \pm 7.35$.

Since previous literature by Friberg et al. has shown that the density of the host bone bed and bone quality are factors affecting resonance frequency reporting [72], we selected an ABS material with an approximate density of
$1.05 \mathrm{~g} / \mathrm{cm}^{3}$. While this material resulted in a moderate to large coefficient of determination when screw torque, resonance frequency, fixation location, and the interaction between screw torque and resonance frequency were compared with mechanical pushout forces (Tables 2-3), the material type selected did not entirely replicate the density of cortical bone, which is reported to be $2.06 \mathrm{~g} / \mathrm{cm}^{3}$ in human femurs [74]. The discrepancy in material selection may have accounted for the adjusted coefficients of determination of 0.67 in the multiple linear regressions, which are considered to be a moderate-to-high-positive correlation [75], but may have been even larger if a different material type had been selected to help validate the model. However, a positive correlation between ISQ values and screw torque has been previously reported in an in vitro model and demonstrates the consistency of our model with previous studies [60]. Further investigation using fresh cadaveric bone samples is planned in the future and will serve to validate our current model.

In our experiment, the force required for implant removal was affected by the points of fixation, as indicated by significance between Hole B and Hole C, respectively. While a statistical relationship was not found for all hole locations, varying degrees of implant stability based on the distance of the Smartpeg to the proximal bone bed surface have been reported previously [55]. According to manufacturer specifications, "a change of about $3 \mathrm{ISQ} / \mathrm{mm}$ should be expected if implants are placed in the same bone density" [55]. However, investigation of Table 1 indicates that this trend was not observed in our model and may be due to implant geometry, which has been reported as a factor affecting stiffness in dental and orthopedic implants $[60,76]$. The hexagonal head of the implant allowed the Smartpeg to stay within the same distance to the ABS material, but the fixation point differed 
in $5 \mathrm{~mm}$ increments between hole locations. The rationale for including the hexagonal head in the model was that it allowed for reproducibility by preventing implant migration which would lead to confounding variables. However, there is reason to believe that a threaded design may have also allowed accurate data collection but would have required fabrication of multiple ABS constructs and screws because of anticipated damage to the screw threads during pushout tests.

While the data collected in the model was initially targeted at proving safety and efficacy in long bone medullary canals, high correlations between resonance frequency and mechanical pushout forces demonstrate the utility of the device for future use in short bones (digits) and low load-bearing implants (facial reconstruction). In all these cases, the biomechanical behavior of osseointegrated implants is vital for firm skeletal attachment [77], since stress must be applied gradually over time to prevent over- or underloading. In addition, to further reduce the likelihood of osseointegration failure due to high interfacial shear stresses, this model may provide useful boundary conditions for finite element models using our mechanical pushout forces as primary stability estimations.

Limitations of the ABS construct used in our model include the restrictions of torques exceeding $10.9 \mathrm{~N} \cdot \mathrm{cm}$ because of the elastic limit of the setscrews and the inability to determine the effect of resonance frequency on mechanical pushout with primary and secondary implant stability. The relationship determined in this study demonstrated a strong positive correlation between resonance frequency ISQ values and mechanical pushout forces but requires in vitro cadaveric validation and in vivo experimentation in long bones to monitor the degree of osseointegration over time with biomechanical testing.

\section{CONCLUSIONS}

The relationship between resonance frequency ISQ values and the force required for implant removal in a nonuniform bone-implant interface model had not been evaluated before this investigation. Orthopedic implants in human medullary canals often result in a nonuniform bone-implant interface [78], and this limits the speed of rehabilitation for individuals with limb loss. While our investigation used an in vitro testing modality, a clear distinction was evident from multiple linear regressions, which demonstrated that the interaction between reso- nance frequency and screw torque correlated with mechanical pushout forces. The simulated approach allowed for controlled loading at separate contact points to represent partial osseointegration, reaffirmed the utility of resonance frequency as an advocated nondestructive mechanical assessment of skeletal fixation, and demonstrated a direct relationship with implant displacements. While the exact force required for implant removal may not be necessary in dental applications, based on our findings in this in vitro model, RFA appears to hold promise for application as a rehabilitation tool for determining implant strength and stability following osseointegration implant placement, and this technology deserves further human cadaveric and in vivo investigation.

\section{ACKNOWLEDGMENTS}

\section{Author Contributions:}

Study concept and design: T. G. Rosenbaum Chou, K. N. Bachus. Acquisition of data: B. M. Isaacson, R. E. Vance.

Analysis and interpretation of data: B. M. Isaacson, R. E. Vance. Drafting of manuscript: B. M. Isaacson.

Critical revision of manuscript for important intellectual content: K. N. Bachus, R. D. Bloebaum, J. B. Webster.

Statistical analysis: B. M. Isaacson.

Obtained funding: J. B. Webster.

Administrative, technical, or material support: R. D. Bloebaum. Study supervision: J. B. Webster.

Financial Disclosures: The Osstell device and Smartpegs used in the study were donated by Anders Petersson, Chief Executive Officer of Osstell AB.

Funding/Support: This material was based on work supported (or supported in part) by the Department of Veterans Affairs (VA) Office of Research and Development, Rehabilitation Research and Development Service, VA Salt Lake City Health Care System, Salt Lake City, UT; the Albert \& Margaret Hofmann Chair and the Department of Orthopaedics, University of Utah School of Medicine, Salt Lake City, UT; and University of Utah Center for Rehabilitation Research (grant CRR-06-PMR), Department of Physical Medicine and Rehabilitation, University of Utah, Salt Lake City, UT.

Additional Contributions: We would like to thank Gregory Stoddard for assistance with and interpretation of statistical analysis; Gwenevere Shaw for support with manuscript preparation; and Anders Petersson, Chief Executive Officer of Osstell AB, for generously providing an Osstell Mentor and Smartpegs for the experiment.

\section{REFERENCES}

1. Albrektsson T, Albrektsson B. Osseointegration of bone implants. A review of an alternative mode of fixation. Acta Orthop Scand. 1987;58(5):567-77. [PMID: 3321881] 
2. Brånemark PI. Osseointegration and its experimental background. J Prosthet Dent. 1983;50(3):399-410.

[PMID: 6352924]

DOI:10.1016/S0022-3913(83)80101-2

3. Brånemark R, Brånemark PI, Rydevik B, Myers RR. Osseointegration in skeletal reconstruction and rehabilitation: A review. J Rehabil Res Dev. 2001;38(2):175-81. [PMID: 11392650]

4. Pitkin M. On the way to total integration of prosthetic pylon with residuum. J Rehabil Res Dev. 2009;46(3):345-60.

[PMID: 19675987] DOI:10.1682/JRRD.2008.08.0112

5. Staubach KH, Grundei H. [The first osseointegrated percutaneous prosthesis anchor for above-knee amputees]. Biomed Tech (Berl). 2001;46(12):355-61. German. [PMID: 11820163] DOI:10.1515/bmte.2001.46.12.355

6. Brånemark PI, Gröndahl HG, Brånemark BK. Why osseointegration would work and how it did in the first patients treated. Basic facts and philosophical thoughts. In: Brånemark PI, editor. The osseointegration book: From calvarium to calcaneus. Berlin (Germany): Quintessence; 2005.

7. Brånemark PI, Adell R, Breine U, Hansson BO, Lindström J, Ohlsson A. Intra-osseous anchorage of dental prostheses. I. Experimental studies. Scand J Plas Reconstr Surg. 1969; 3(2):81-100. [PMID: 4924041]

\section{DOI:10.3109/02844316909036699}

8. Jemt T. Failures and complications in 391 consecutively inserted fixed prostheses supported by Brånemark implants in edentulous jaws: A study of treatment from the time of prosthesis placement to the first annual checkup. Int J Oral Maxillofac Implants. 1991;6(3):270-76. [PMID: 1813395$]$

9. Kegel B, Carpenter ML, Burgess EM. Functional capabilities of lower extremity amputees. Arch Phys Med Rehabil 1978;59(3):109-20. [PMID: 646596]

10. Rommers GM, Vos LD, Groothoff JW, Eisma WH. Mobility of people with lower limb amputations: Scales and questionnaires: A review. Clin Rehabil. 2001;15(1):92-102. [PMID: 11237166] DOI:10.1191/026921501677990187

11. Aaron RK, Herr HM, Ciombor DM, Hochberg LR, Donoghue JP, Briant CL, Morgan JR, Ehrlich MG. Horizons in prosthesis development for the restoration of limb function. J Am Acad Orthop Surg. 2006;14(10 Spec No.):S198-204. [PMID: 17003199]

12. Hagberg K, Brånemark R. Consequences of non-vascular trans-femoral amputation: A survey of quality of life, prosthetic use and problems. Prosthet Orthot Int. 2001;25(3): 186-94. [PMID: 11860092] DOI:10.1080/03093640108726601

13. Isaacson BM, Stinstra JG, MacLeod RS, Webster JB, Beck JP, Bloebaum RD. Bioelectric analyses of an osseointe- grated intelligent implant design system for amputees. J Vis Exp. 2009(29):1-6. [PMID: 19609251]

14. Albrektsson T, Brånemark PI, Hansson HA, Lindström J. Osseointegrated titanium implants. Requirements for ensuring a long-lasting, direct bone-to-implant anchorage in man. Acta Orthop Scand. 1981;52(2):155-70. [PMID: 7246093]

15. Meyer U, Joos U, Mythili J, Stamm T, Hohoff A, Fillies T, Stratmann U, Wiesmann HP. Ultrastructural characterization of the implant/bone interface of immediately loaded dental implants. Biomaterials. 2004;25(10):1959-67.

[PMID: 14738860]

DOI:10.1016/j.biomaterials.2003.08.070

16. Hofmann AA, Bloebaum RD, Bachus KN. Progression of human bone ingrowth into porous-coated implants. Rate of bone ingrowth in humans. Acta Orthop Scand. 1997;68(2): 161-66. [PMID: 9174454]

17. Slaets E, Naert I, Carmeliet G, Duyck J. Early cortical bone healing around loaded titanium implants: A histological study in the rabbit. Clin Oral Implants Res. 2009;20(2): 126-34. [PMID: 19191791] DOI:10.1111/j.1600-0501.2008.01623.x

18. Duyck J, Vandamme K, Geris L, Van Oosterwyck H, De Cooman M, Vandersloten J, Puers R, Naert I. The influence of micro-motion on the tissue differentiation around immediately loaded cylindrical turned titanium implants. Arch Oral Biol. 2006;51(1):1-9. [PMID: 15922992]

DOI:10.1016/j.archoralbio.2005.04.003

19. Szmukler-Moncler S, Salama H, Reingewirtz Y, Dubruille JH. Timing of loading and effect of micromotion on bonedental implant interface: Review of experimental literature. J Biomed Mater Res. 1998;43(2):192-203.

[PMID: 9619438] DOI:10.1002/(SICI)1097-4636(199822)43:2<192::AIDJBM14>3.0.CO;2-K

20. Glauser R, Sennerby L, Meredith N, Rée A, Lundgren A, Gottlow J, Hämmerle $\mathrm{CH}$. Resonance frequency analysis of implants subjected to immediate or early functional occlusal loading. Successful vs. failing implants. Clin Oral Implants Res. 2004;15(4):428-34. [PMID: 15248877] DOI:10.1111/j.1600-0501.2004.01036.x

21. Meredith N, Alleyne D, Cawley P. Quantitative determination of the stability of the implant-tissue interface using resonance frequency analysis. Clin Oral Implants Res. 1996;7(3):261-67. [PMID: 9151590] DOI:10.1034/j.1600-0501.1996.070308.x

22. Röser K, Johansson CB, Donath K, Albrektsson T. A new approach to demonstrate cellular activity in bone formation adjacent to implants. J Biomed Mater Res. 2000;51(2): 280-91. [PMID: 10825228] DOI:10.1002/(SICI)1097-4636(200008)51:2<280::AID$\underline{\mathrm{JBM} 17>3.0 . \mathrm{CO} ; 2-\mathrm{L}}$ 
23. Nkenke E, Lehner B, Weinzierl K, Thams U, Neugebauer J, Steveling H, Radespiel-Tröger M, Neukam FW. Bone contact, growth, and density around immediately loaded implants in the mandible of mini pigs. Clin Oral Implants Res. 2003;14(3):312-21. [PMID: 12755781] DOI:10.1034/j.1600-0501.2003.120906.X

24. Slaets E, Carmeliet G, Naert I, Duyck J. Early trabecular bone healing around titanium implants: A histologic study in rabbits. J Periodontol. 2007;78(3):510-17.

[PMID: 17335375]

DOI:10.1902/jop.2007.060183

25. Piattelli A, Corigliano M, Scarano A, Costigliola G, Paolantonio M. Immediate loading of titanium plasma-sprayed implants: An histologic analysis in monkeys. J Periodontol. 1998;69(3):321-27. [PMID: 9579618]

26. Vandamme K, Naert I, Vander Sloten J, Puers R, Duyck J. Effect of implant surface roughness and loading on periimplant bone formation. J Periodontol. 2008;79(1):150-57. [PMID: 18166105] DOI:10.1902/jop.2008.060413

27. Peñarrocha $M$, Boronat $A$, Garcia B. Immediate loading of immediate mandibular implants with a full-arch fixed prosthesis: A preliminary study. J Oral Maxillofac Surg. 2009; 67(6):1286-93. [PMID: 19446218

DOI:10.1016/j.joms.2008.12.024

28. Abrahamsson I, Linder E, Lang NP. Implant stability in relation to osseointegration: An experimental study in the Labrador dog. Clin Oral Implants Res. 2009;20(3):313-18. [PMID: 19405177] DOI:10.1111/j.1600-0501.2008.01646.x

29. Søballe K, Hansen ES, B-Rasmussen H, Jørgensen PH, Bünger $\mathrm{C}$. Tissue ingrowth into titanium and hydroxyapatite-coated implants during stable and unstable mechanical conditions. J Orthop Res. 1992;10(2):285-99.

[PMID: 1311039]

DOI:10.1002/jor.1100100216

30. Adell R, Hansson BO, Brånemark PI, Breine U. Intraosseous anchorage of dental prostheses. II. Review of clinical approaches. Scand J Plast Reconstr Surg. 1970;4(1):19-34. [PMID: 4920517]

DOI:10.3109/02844317009038440

31. Rafel SS. Temperature changes during high-speed drilling on bone. J Oral Surg Anesth Hosp Dent Serv. 1962;20: 475-77. [PMID: 13990417]

32. Taylor TD. Prosthodontic problems and limitations associated with osseointegration. J Prosthet Dent. 1998;79(1):74-78. [PMID: 9474545] DOI:10.1016/S0022-3913(98)70197-0

33. Bloebaum RD, Rubman MH, Hofmann AA. Bone ingrowth into porous-coated tibial components implanted with autograft bone chips: Analysis of ten consecutively retrieved implants. J Arthroplasty. 1992;7(4):483-93.

[PMID: 1479367]
34. Pilliar RM, Lee JM, Maniatopoulos C. Observations on the effect of movement on bone ingrowth into porous-surfaced implants. Clin Orthop Relat Res. 1986;(208):108-13. [PMID: 3720113$]$

35. Kieswetter K, Schwartz Z, Dean DD, Boyan BD. The role of implant surface characteristics in the healing of bone. Crit Rev Oral Biol Med. 1996;7(4):329-45. [PMID: 8986395] DOI:10.1177/10454411960070040301

36. Brånemark PI, Albrektsson T. Titanium implants permanently penetrating human skin. Scand J Plast Reconstr Surg. 1982;16(1):17-21. [PMID: 7112035] DOI:10.3109/02844318209006565

37. Bloebaum RD, Bachus KN, Momberger NG, Hofmann AA. Mineral apposition rates of human cancellous bone at the interface of porous coated implants. J Biomed Mater Res. 1994;28(5):537-44. [PMID: 8027094]

DOI:10.1002/jbm.820280503

38. Bloebaum RD, Bachus KN, Rubman MH, Dorr LD. Postmortem comparative analysis of titanium and hydroxyapatite porous coated femoral implants retrieved from the same patient. J Arthroplasty. 1993;8(2):203-11.

[PMID: 8386749] DOI:10.1016/S0883-5403(09)80014-4

39. Vandamme K, Naert I, Geris L, Sloten JV, Puers R, Duyck $\mathrm{J}$. Histodynamics of bone tissue formation around immediately loaded cylindrical implants in the rabbit. Clin Oral Implants Res. 2007;18(4):471-80. [PMID: 17517061] DOI:10.1111/j.1600-0501.2007.01339.x

40. Uhthoff HK, Germain JP. The reversal of tissue differentiation around screws. Clin Orthop Relat Res. 1977;(123): 248-52. [PMID: 856516]

41. Hagberg K, Brånemark R, Gunterberg B, Rydevik B. Osseointegrated trans-femoral amputation prostheses: Prospective results of general and condition-specific quality of life in 18 patients at 2-year follow-up. Prosthet Orthot Int. 2008;32(1):29-41. [PMID: 18330803] DOI:10.1080/03093640701553922

42. Frossard L, Lee Gow D, Contoyannis B, Ewins D, Sullivan J, Tranberg R, Haggstrom E, Brånemark R. Loading applied to the implant of transfemoral amputees fitted with a direct skeletal fixation during load bearing exercises. Fourth Australasian Biomechanics Conference; 2002 Nov 28-30; Melbourne, Australia. Melbourne (Australia): La Trobe University; 2002.

43. Bloebaum RD, Willie BM, Mitchell BS, Hofmann AA. Relationship between bone ingrowth, mineral apposition rate, and osteoblast activity. J Biomed Mater Res A. 2007; 81(2):505-14. [PMID: 17236212 ]

DOI:10.1002/jbm.a.31087

44. Oh JS, Kim SG, Lim SC, Ong JL. A comparative study of two noninvasive techniques to evaluate implant stability: Periotest and Osstell Mentor. Oral Surg Oral Med Oral Pathol Oral Radiol Endod. 2009;107(4):513-18. 
[PMID: 19095473]

DOI:10.1016/j.tripleo.2008.08.026

45. Slaets E, Carmeliet G, Naert I, Duyck J. Early cellular responses in cortical bone healing around unloaded titanium implants: An animal study. J Periodontol. 2006;77(6): 1015-24. [PMID: 16734577] DOI:10.1902/jop.2006.050196

46. Zhou Y, Jiang T, Qian M, Zhang X, Wang J, Shi B, Xia H, Cheng $\mathrm{X}$, Wang $\mathrm{Y}$. Roles of bone scintigraphy and resonance frequency analysis in evaluating osseointegration of endosseous implant. Biomaterials. 2008;29(4):461-74.

[PMID: 17983650]

DOI:10.1016/j.biomaterials.2007.10.021

47. Andrés-García R, Vives NG, Climent FH, Palacín AF, Santos VR, Climent MH, Bullón P. In vitro evaluation of the influence of the cortical bone on the primary stability of two implant systems. Med Oral Patol Oral Cir Bucal. 2009; 14(2):E93-97. [PMID: 19179957]

48. Zix J, Lieger O, Iizuka T. Use of straight and curved 3-dimensional titanium miniplates for fracture fixation at the mandibular angle. J Oral Maxillofac Surg. 2007;65(9): 1758-63. [PMID: 17719394] DOI:10.1016/j.joms.2007.03.013

49. Atsumi M, Park SH, Wang HL. Methods used to assess implant stability: Current status. Int J Oral Maxillofac Implants. 2007;22(5):743-54. [PMID: 17974108]

50. Sundén S, Gröndahl K, Gröndahl HG. Accuracy and precision in the radiographic diagnosis of clinical instability in Brånemark dental implants. Clin Oral Implants Res. 1995;6(4):220-26. [PMID: 8603113] DOI:10.1034/j.1600-0501.1995.060404.x

51. Sartoris DJ, Resnick D. Current and innovative methods for noninvasive bone densitometry. Radiol Clin North Am. 1990;28(2):257-78. [PMID: 2408094]

52. Sennerby L, Meredith N. Implant stability measurements using resonance frequency analysis: Biological and biomechanical aspects and clinical implications. Periodontol 2000. 2008;47:51-66. [PMID: 18412573] DOI:10.1111/j.1600-0757.2008.00267.x

53. Kessler-Liechti G, Zix J, Mericske-Stern R. Stability measurements of 1-stage implants in the edentulous mandible by means of resonance frequency analysis. Int J Oral Maxillofac Implants. 2008;23(2):353-58. [PMID: 18548934]

54. Meredith N, Shagaldi F, Alleyne D, Sennerby L, Cawley P. The application of resonance frequency measurements to study the stability of titanium implants during healing in the rabbit tibia. Clin Oral Implants Res. 1997;8(3):234-43. [PMID: 9586468] DOI:10.1034/j.1600-0501.1997.080310.x

55. Turkyilmaz I, Sennerby L, Yilmaz B, Bilecenoglu B, Ozbek EN. Influence of defect depth on resonance frequency analysis and insertion torque values for implants placed in fresh extraction sockets: A human cadaver study.
Clin Implant Dent Relat Res. 2009;11(1):52-58.

[PMID: 18384400]

DOI:10.1111/j.1708-8208.2008.00095.x

56. Balshi SF, Wolfinger GJ, Balshi TJ. An examination of immediately loaded dental implant stability in the diabetic patient using resonance frequency analysis (RFA). Quintessence Int. 2007;38(4):271-79. [PMID: 17432781]

57. Boronat López A, Balaguer Martínez J, Lamas Pelayo J, Carrillo García C, Peñarrocha Diago M. Resonance frequency analysis of dental implant stability during the healing period. Med Oral Patol Oral Cir Bucal. 2008;13(4): E244-47. [PMID: 18379449]

58. Rao W, Benzi R. Single mandibular first molar implants with flapless guided surgery and immediate function: Preliminary clinical and radiographic results of a prospective study. J Prosthet Dent. 2007;97(6 Suppl):S3-S14.

[PMID: 17618931]

DOI:10.1016/S0022-3913(07)60003-1

59. Ratner BD, Hoffman AS, Schoen FJ, Lemons JE. Biomaterials science: An introduction to materials in medicine. 2nd ed. Boston (MA): Elsevier Academic Press; 2004. p. 543.

60. Tözüm TF, Turkyilmaz I, McGlumphy EA. Relationship between dental implant stability determined by resonance frequency analysis measurements and peri-implant vertical defects: An in vitro study. J Oral Rehabil. 2008;35(10): 739-44. [PMID: 18422511] DOI:10.1111/j.1365-2842.2007.01840.x

61. Capek L, Simunek A, Slezak R, Dzan L. Influence of the orientation of the Osstell transducer during measurement of dental implant stability using resonance frequency analysis: A numerical approach. Med Eng Phys. 2009;31(7): 764-69. [PMID: 19297232]

DOI:10.1016/j.medengphy.2009.02.003

62. Kuo TY, Skedros JG, Bloebaum RD. Comparison of human, primate, and canine femora: Implications for biomaterials testing in total hip replacement. J Biomed Mater Res. 1998;40(3):475-89. [PMID: 9570081]

DOI:10.1002/(SICI)1097-4636(19980605)40:3<475::AIDJBM19>3.0.CO;2-I

63. Bloebaum RD, Ota DT, Skedros JG, Mantas JP. Comparison of human and canine external femoral morphologies in the context of total hip replacement. J Biomed Mater Res. 1993;27(9):1149-59. [PMID: 8126013] DOI:10.1002/jbm.820270905

64. Rosenbaum TG, Hamblin T, Bloebaum RD. Determining the degree of cortical bone asymmetry in bilateral, nonpathological, human femur pairs. J Biomed Mater Res A. 2006;76(3):450-55. [PMID: 16270336]

DOI:10.1002/jbm.a.30568

65. Nyman JS, Roy A, Shen X, Acuna RL, Tyler JH, Wang X. The influence of water removal on the strength and toughness of cortical bone. J Biomech. 2006;39(5):931-38. 
[PMID: 16488231]

DOI:10.1016/j.jbiomech.2005.01.012

66. Pospula W, Noor TA, Al Rowaih A. Cementless Zweymüller hip replacement: A short-term follow-up in Al Razi Hospital, Kuwait. Med Princ Pract. 2005;14(4):255-59.

[PMID: 15961936]

DOI:10.1159/000085745

67. Vervest TM, Anderson PG, Van Hout F, Wapstra FH, Louwerse RT, Koetsier JW. Ten to twelve-year results with the Zweymüller cementless total hip prosthesis. J Arthroplasty. 2005;20(3):362-68. [PMID: 15809956] DOI:10.1016/j.arth.2004.11.017

68. Beder OE, Eade G. An investigation of tissue tolerance to titanium metal implants in dogs. Surgery. 1956;39(3):470-73. [PMID: 13299000]

69. Emnéus H, Gudmundsson G. Final report on the clinical testing of titanium. Acta Orthop Scand. 1967;38(1):372-73. Available from: http://pdfserve.informaworld.com/67884 7 68420410 784865168.pdf/.

70. Martin AD, Driscoll CL, Wood CP, Felmlee JP. Safety evaluation of titanium middle ear prostheses at 3.0 tesla. Otolaryngol Head Neck Surg. 2005;132(4):537-42. [PMID: 15806041] DOI:10.1016/j.otohns.2004.12.003

71. Wichmann W, Von Ammon K, Fink U, Weik T, Yasargil GM. Aneurysm clips made of titanium: Magnetic characteristics and artifacts in MR. AJNR Am J Neuroradiol. 1997; 18(5):939-44. [PMID: 9159374]

72. Friberg B, Jemt T, Lekholm U. Early failures in 4,641 consecutively placed Brånemark dental implants: A study from stage 1 surgery to the connection of completed prostheses.
Int J Oral Maxillofac Implants. 1991;6(2):142-46. [PMID: 1809668]

73. Ward DA, Robinson KP. Osseointegration for the skeletal fixation of limb prostheses in amputations at the transfemoral level. In: Brånemark PI, editor. The osseointegration book: From calvarium to calcaneus. Berlin (Germany): Quintessence; 2005. p. 463-76.

74. Currey JD. Mechanical properties of bone tissues with greatly differing functions. J Biomech. 1979;12(4):313-19.

[PMID: 468855] DOI:10.1016/0021-9290(79)90073-3

75. Hinkle DE, Wiersma W, Jurs SG. Applied statistics for the behavioral sciences. 5th ed. Boston (MA): Houghton Mifflin; 2003.

76. Dhert WJ, Verheyen CC, Braak LH, De Wijn JR, Klein CP, De Groot K, Rozing PM. A finite element analysis of the push-out test: Influence of test conditions. J Biomech Meter Res. 1992;26(1):119-30. [PMID: 1577832] DOI:10.1002/jbm.820260111

77. Brånemark R, Skalak R. An in-vivo method for biomechanical characterization of bone-anchored implants. Med Eng Phys. 1998;20(3):216-19. [PMID: 9690492] DOI:10.1016/S1350-4533(98)00023-X

78. Rosenbaum TG, Bloebaum RD, Ashrafi S, Lester DK. Ambulatory activities maintain cortical bone after total hip arthroplasty. Clin Orthop Relat Res. 2006;450:129-37.

[PMID: 16721349] DOI:10.1097/01.blo.0000223981.21584.35

Submitted for publication June 19, 2009. Accepted in revised form October 14, 2009. 